\title{
Hydrogen Bonding Effect on the Poly(ethylene oxide), Phenolic Resin, and Lithium Perchlorate-Based Solid-State Electrolyte
}

\author{
Hsien-Wei Chen, Chang-Hung Jiang, Hew-Der Wu, Feng-Chih Chang \\ Institute of Applied Chemistry, National Chiao-Tung University, Hsin-Chu, 30043, Taiwan, Republic of China
}

Received 30 August 2002; accepted 9 June 2003

\begin{abstract}
The interaction behavior of solid-state polymer electrolytes composed of poly(ethylene oxide) (PEO)/ novolac-type phenolic resin and lithium perchlorate $(\mathrm{Li}-$ $\mathrm{ClO}_{4}$ ) was investigated in detail by DSC, FTIR, ac impedance, DEA, solid-state NMR, and TGA. The hydrogen bonding between the hydroxyl group of phenolic and ether oxygen of the PEO results in higher basicity of the PEO. The higher basicity of the ether group can dissolve the lithium salts more easily and results in a greater fraction of "free" anions and thus higher ionic conductivity. DEA results demonstrated that addition of the phenolic increases the dielec-
\end{abstract}

tric constant because of the partially negative charge on the ether group induced by the hydrogen bonding interaction between ether oxygen and the hydroxyl group. The study showed that the blend of $\mathrm{PEO}(100) / \mathrm{LiClO}_{4}(25) /$ phenolic(15) possesses the highest ionic conductivity $\left(1.5 \times 10^{-5} \mathrm{~S}\right.$ $\mathrm{cm}^{-1}$ ) with dimensional stability. (c) 2003 Wiley Periodicals, Inc. J Appl Polym Sci 91: 1207-1216, 2004

Key words: poly(ethylene oxide) (PEO); resins; hydrogen bonding; ionic conductivity; solid-state structure

\section{INTRODUCTION}

Since the original work of Wright and Armand on poly(ethylene oxide) (PEO)/alkali metal salt-based solid polymer electrolytes (SPEs), ${ }^{1-4}$ research efforts for improvement of ionic conductivity have become quite active. During the past decade, lithium saltbased electrolytes have been the focus of numerous fundamental and application-oriented studies. ${ }^{5-10}$ Most research has focused on the development of high power and high energy density secondary lithium batteries with major concerns directed to performance, safety, and reliability. Applications of lithium batteries in automotive industries, portable devices, and aerospace applications are presently a subject of great interest.

PEO-based polymer electrolytes are still among the most extensively studied polymer ionic conductors because of the beneficial structure in supporting fast ion transport. ${ }^{711-13}$ Two approaches for achieving high conductivity of PEO-based SPE are the suppression of PEO crystallization to improve the chain mobility and increase of the charge carrier. Chu et al. ${ }^{18}$ reported that the addition of phenolic resin can enhance the conductivity because of the reduced PEO crystallinity and lower pseudoactivation energy in lithium transfer of the blend. However, in addition to

Correspondence to: F.-C. Chang (changfc@cc.nctu.edu.tw).

Journal of Applied Polymer Science, Vol. 91, 1207-1216 (2004) (C) 2003 Wiley Periodicals, Inc. the hydrogen bonding interaction, the specific interactions between the phenolic resin, PEO, and lithium salts were not discussed. In this study, we attempted to add the novolac phenolic to the $\mathrm{PEO} / \mathrm{LiClO}_{4}$ electrolyte system by suppressing PEO crystallization through strong hydrogen bonding interaction between the ether group of PEO and the hydroxyl group of the novolac phenolic. The obtained blend of $\mathrm{PEO}(100) / \mathrm{LiClO} 4(25) /$ phenolic(15) possesses high ionic conductivity of $1.5 \times 10^{-5} \mathrm{~S} \mathrm{~cm}^{-1}$ at room temperature and elastic property. Based on IR spectra of $\mathrm{OH}^{-}$and $\mathrm{ClO}_{4}^{-}$vibrations, the increase in conductivity is not only from the increase in amorphous fraction but also from the complicated interaction among PEO, phenolic, and lithium salt. These IR vibrations were used to interpret the complicated interaction mechanism among PEO, phenolic, and the lithium salt. The purpose of this work was to emphasize the effect on the fraction of hydrogen bonding by adding phenolic to provide the $\mathrm{PEO} / \mathrm{LiClO}_{4} /$ phenolic blend system.

\section{EXPERIMENTAL}

\section{Sample preparation}

The novolac-type phenolic resin was synthesized and analyzed as described previously. ${ }^{19}$ The chemical structure of the novolac-type phenolic resin consists of phenol rings bridge-linked randomly by methylene groups with $19 \%$ ortho-ortho, $57 \%$ ortho-para, and $24 \%$ para-para methylene bridges as identified by solution ${ }^{13} \mathrm{C}$-NMR. The poly(ethylene oxide) (PEO) with $M_{n}$ of 
TABLE I

Desired Amount for PEO(100)/Li(25)/Phenolic(x)

\begin{tabular}{lcccccc}
\hline & \multicolumn{5}{c}{ Weight fraction (wt \%) for PEO, Li, and phenolic } \\
\cline { 2 - 6 } Component & \multicolumn{5}{c}{ Phenolic concentration $(x)$} \\
\cline { 2 - 6 } \multicolumn{1}{c}{ (wt) } & 0 & 5 & 10 & 15 & 20 & 25 \\
\hline PEO (100 g) & $80.0 \%$ & $76.9 \%$ & $74.1 \%$ & $71.4 \%$ & $69.0 \%$ & $66.7 \%$ \\
Li (25 g) & $20.0 \%$ & $19.2 \%$ & $18.5 \%$ & $28.6 \%$ & $17.2 \%$ & $16.7 \%$ \\
Phenolic $(x \mathrm{~g})$ & $0 \%$ & $3.8 \%$ & $7.4 \%$ & $10.7 \%$ & $13.8 \%$ & $16.7 \%$ \\
\hline
\end{tabular}

200,000 was obtained from Aldrich (Milwaukee, WI). The lithium perchlorate salt $\left(\mathrm{LiClO}_{4}\right)$, also obtained from Aldrich, was dried in a vacuum oven at $80^{\circ} \mathrm{C}$ for $24 \mathrm{~h}$, and then stored in a desiccator before use. The $\mathrm{N}, \mathrm{N}$-dimethyl formamide (DMF) was refluxed at a suitable temperature under nitrogen atmosphere before use.

\section{Preparation of solid polymer electrolytes (SPEs)}

The $\mathrm{PEO} / \mathrm{LiClO}_{4} /$ phenolic complexes of different compositions were prepared by dissolving the desired amount of the PEO (Table I), vacuum dried $\mathrm{LiClO}_{4}$ salt, and phenolic in dry DMF. After continuous stirring for $24 \mathrm{~h}$ at $60^{\circ} \mathrm{C}$, these solutions were maintained at $130^{\circ} \mathrm{C}$ for $24 \mathrm{~h}$ to facilitate solvent removal, and then further dried under vacuum at $80^{\circ} \mathrm{C}$ for another 3 days. The samples were analyzed by FTIR (carbonyl group, $1700 \mathrm{~cm}^{-1}$ ) to monitor the residual solvent. All of these complexes were stored in a dry box filled with nitrogen atmosphere to prevent contact with air and moisture.

The phr unit was used as the formulae in this study. For example, $\mathrm{PEO}(100) / \mathrm{LiClO}_{4}(15)$ means $\mathrm{PEO}$ is nearly $87 \mathrm{wt} \%$; however, the $\mathrm{LiClO}_{4}$ is $13 \mathrm{wt} \%$.

\section{DSC measurements}

Thermal property measurements were carried out on a DSC 2010 (TA Instruments, New Castle, DE). The measurements were conducted under a nitrogen atmosphere with a flow rate of about $25 \mathrm{~mL} \mathrm{~min}^{-1}$ and the instrument was calibrated with an indium standard. All samples were annealed for $10 \mathrm{~min}$ at $100^{\circ} \mathrm{C}$ and then rapidly quenched to $-100^{\circ} \mathrm{C}$ and then reheated. A heating rate of $10^{\circ} \mathrm{C} \mathrm{min}{ }^{-1}$ was used in all cases. The glass-transition temperature $\left(T_{g}\right)$ and the crystallization temperature $\left(T_{c}\right)$ were taken as the midpoint of the transition and the minimum of the exothermic peak, respectively, whereas the melt-point temperature $\left(T_{m}\right)$ was taken as the maximum of the endothermic peak.

\section{FTIR measurements}

Infrared spectra of composite films were measured using the conventional $\mathrm{NaCl}$ disk method. All poly- mer films were prepared under $\mathrm{N}_{2}$ atmosphere. The DMF solution of the complex was cast onto a $\mathrm{NaCl}$ disk and the solvent was removed under vacuum at $70^{\circ} \mathrm{C}$ for $48 \mathrm{~h}$. All infrared spectra were obtained with wavenumbers in the range of $4000-400 \mathrm{~cm}^{-1}$ with a resolution of $1 \mathrm{~cm}^{-1}$ on a Nicolet Avatar 320 FTIR spectrometer (Nicolet Analytical Instruments, Madison, WI).

\section{Conductivity measurements}

Ionic conductivity measurements with alternating current (ac) were conducted on an Autolab designed by Eco Chemie in the frequency range from $10 \mathrm{MHz}$ to 10 $\mathrm{Hz}$. The composite film was sandwiched between stainless-steel blocking electrodes (1 $\mathrm{cm}$ diameter). The specimen thickness was about $100 \mu \mathrm{m}$, and the impedance response was measured over the range from 27 to $80^{\circ} \mathrm{C}$.

\section{Dielectric constant analyses}

Dielectric constants of composites were measured at different temperatures (from 25 to $40^{\circ} \mathrm{C}$ ) using a TA Instruments DEA 2970 at the frequency of $100 \mathrm{~Hz}$. The specimen thickness varied from 0.2 to $0.3 \mathrm{~mm}$.

\section{TGA measurements}

A TG/DTA 200 thermal gravimetric analyzer (Seiko Instruments, Japan) was used to carry out the TGA experiments on the weight loss and thermal decomposition behavior for $\mathrm{PEO} / \mathrm{LiClO}_{4} /$ phenolic electrolytes in this study. The heating rate was $10^{\circ} \mathrm{C} \mathrm{min}^{-1}$, from 30 to $600^{\circ} \mathrm{C}$, under nitrogen atmosphere.

\section{Solid-state NMR characterizations}

High-resolution solid-state ${ }^{7} \mathrm{Li}-\mathrm{NMR}$ experiments were carried out on a Bruker DSX-400 spectrometer (Bruker Instruments, Billerica, MA) operating at a resonance frequency of $155.5 \mathrm{MHz}$. The ${ }^{7} \mathrm{Li}$ magic angle spinning (MAS) spectra were measured with $3 \mu \mathrm{s}, 90^{\circ}$ pulse angle, 2-s pulse delay time, 2048 scans, and spinning speed $3 \mathrm{kHz}$. All NMR spectra were taken at $27^{\circ} \mathrm{C}$ with proton decoupling and MAS of $10 \mathrm{kHz}$. 


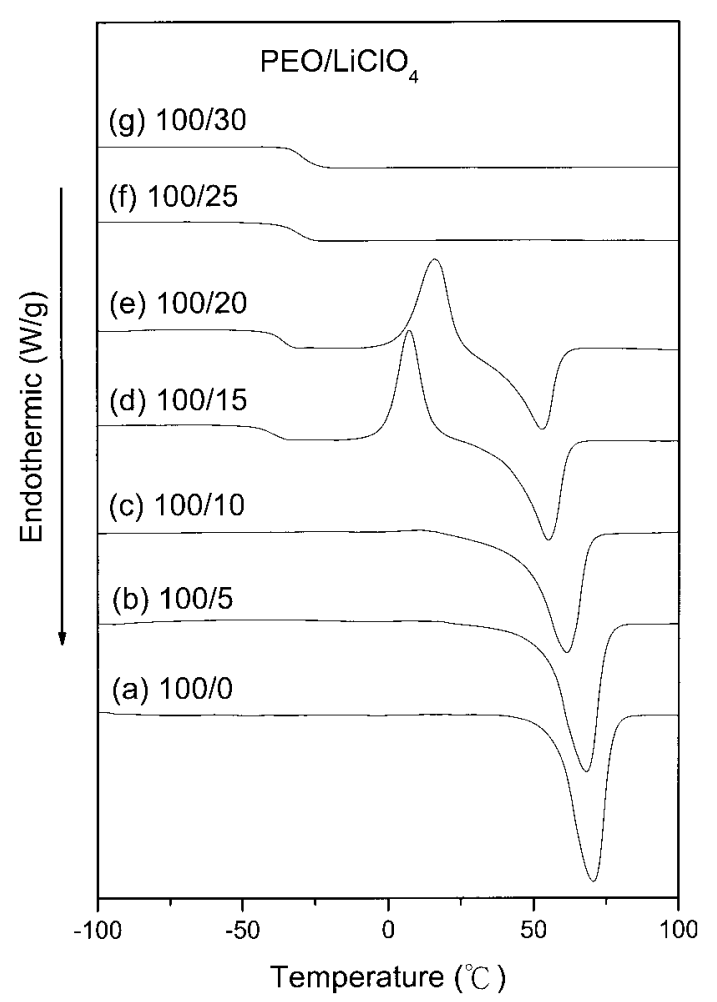

Figure 1 DSC thermograms of the $\mathrm{PEO} / \mathrm{LiClO}_{4}$ blends: (a) $100 / 0$; (b) $100 / 5$; (c) $100 / 10$; (d) $100 / 15$; (e) $100 / 20$; (f) $100 /$ $25 ;(\mathrm{g}) 100 / 30$.

\section{RESULTS AND DISCUSSION}

\section{Thermal properties of solid polymer electrolytes}

Figure 1 shows the DSC thermograms of $\mathrm{PEO} / \mathrm{LiClO}_{4}$ electrolyte systems with various concentrations of the lithium salt. Thermograms of plain PEO, PEO(100)/
$\mathrm{LiClO}_{4}(5)$, and $\mathrm{PEO}(100) / \mathrm{LiClO}_{4}(10)$ show a single endothermic peak appearing around $70^{\circ} \mathrm{C}$, corresponding to the PEO melting peak, an indication of full development of PEO crystallization. By the addition of lithium salts, the melting temperature $\left(T_{m}\right)$ and heat enthalpy of the PEO decreased slightly with increasing $\mathrm{LiClO}_{4}$ content. Mixtures of $\mathrm{PEO}(100) / \mathrm{Li}-$ $\mathrm{ClO}_{4}(15)$ and $\mathrm{PEO}(100) / \mathrm{LiClO}_{4}(20)$ show a $T_{g}$ and both an exothermic and an endothermic peak. As shown in the plot, the mixtures containing 25 and 30 phr $\mathrm{LiClO}_{4}$ give only one $T_{g}$, implying that PEO crystallization is suppressed by the presence of $\mathrm{LiClO}_{4}$. Furthermore, the $T_{g}$ is increased by the increase of $\mathrm{LiClO}_{4}$ content, attributed to the strong interaction of the ethylene oxide group and lithium cation. The appearance of a single $T_{g}$ in $\mathrm{PEO} / \mathrm{LiClO}_{4}$ electrolyte [Fig. $1(\mathrm{f}),(\mathrm{g})]$ strongly suggests that these systems are in a homogeneous single amorphous phase. These thermal properties are consistent with the generally observed behavior of polymer salt electrolytes attributed to the formation of a pseudo-crosslinked system resulting in higher $T_{g}$ with lower PEO crystalline. Because the higher $T_{g}$ means lower chain mobility, the polymer chain will be harder to rotate and rearrange. Therefore, the higher $T_{g}$ results in lower crystallinity. Figure 2 presents the change of $T_{g}$ for the $\mathrm{PEO}(100) / \mathrm{Li}-$ $\mathrm{ClO}_{4}(25) /$ phenolic electrolyte system containing various phenolic concentrations. The $T_{g}$ increases gradually with the increase in phenolic concentration, which increase can be attributed to the strong interhydrogen bonding between hydroxyl groups in the phenolic and ether groups in PEO. ${ }^{15-20}$ The single $T_{g}$ indicates that these $\mathrm{PEO} / \mathrm{LiClO}_{4} /$ phenolic electrolyte blends form a more miscible and fully amorphous material, which will be good for ionic transference.

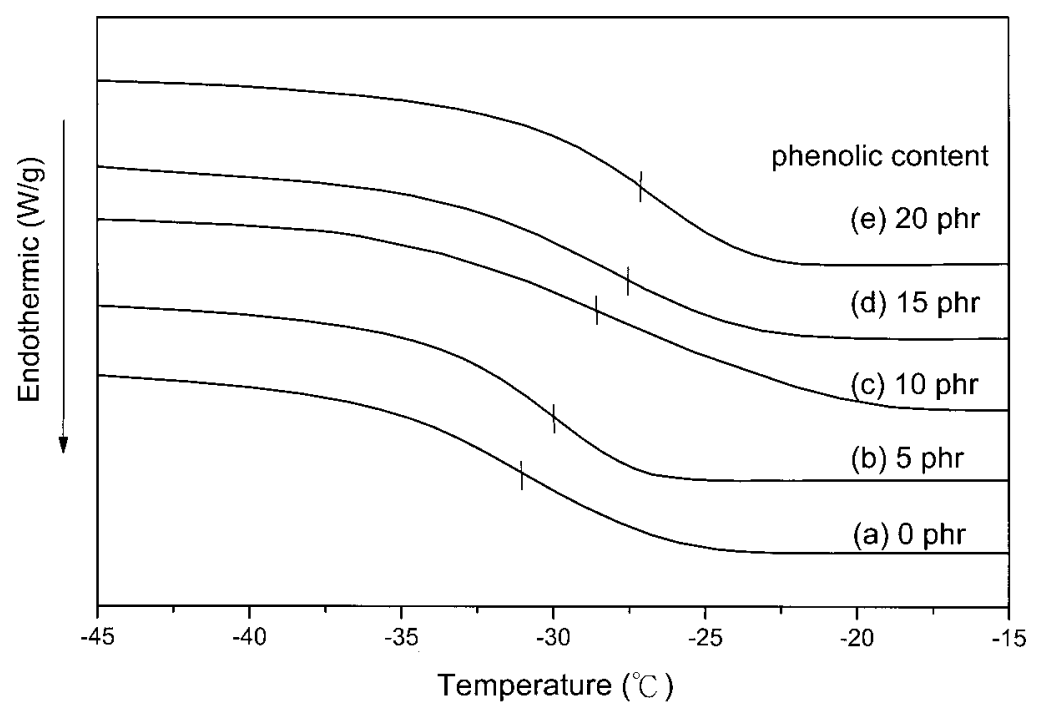

Figure 2 DSC thermograms of $\mathrm{PEO} / \mathrm{LiClO}_{4} /$ phenolic with various phenolic concentrations: (a) 100/25/0; (b) 100/25/5; (c) 100/25/10; (d) 100/25/15; (e) 100/25/20. 


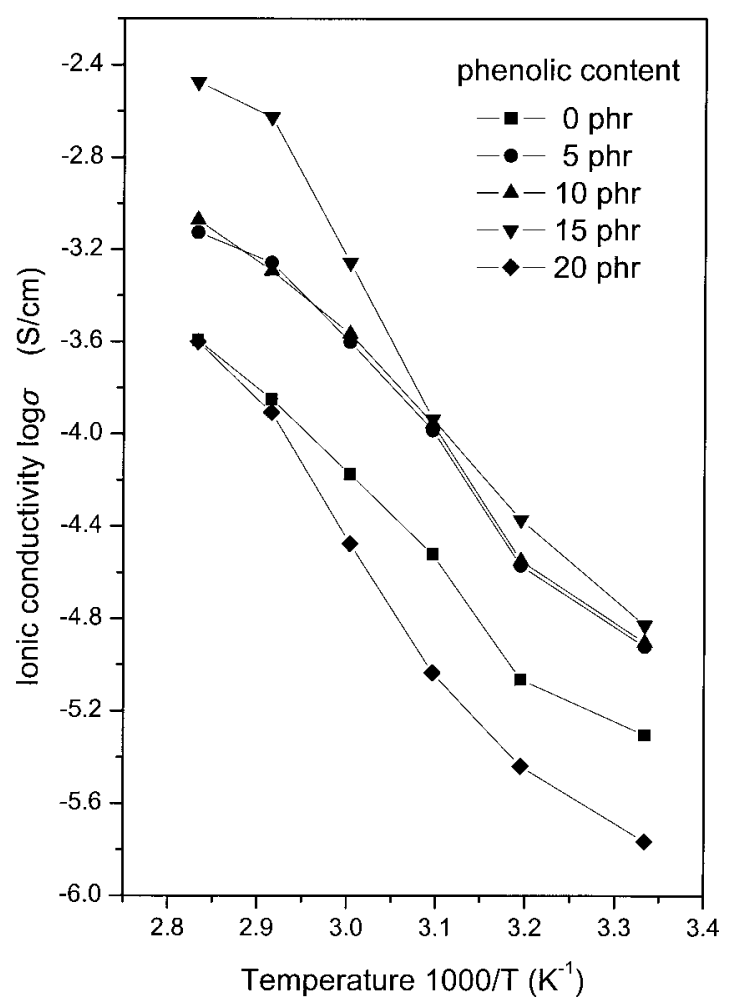

Figure 3 Arrhenius conductivity plots of $\mathrm{PEO} / \mathrm{LiClO}_{4} /$ phenolic with various phenolic concentrations: (口) 100/

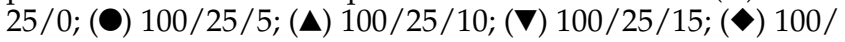
$25 / 20$.

\section{Conductivity}

Figure 3 presents Arrhenius plots that illustrate the temperature dependency of the ionic conductivity for $\mathrm{PEO}(100) / \mathrm{LiClO}_{4}(25) /$ phenolic electrolyte composites containing various phenolic concentrations. The conductivity increases with the increase of the phenolic content and attains a maximum value when the phenolic concentration is at $15 \mathrm{phr}$. Subsequently, the conductivity decreases drastically with further increases of the phenolic content. Figure 4 presents the conductivity isotherms obtained at 40,60 , and $80^{\circ} \mathrm{C}$ for $\mathrm{PEO}(100) / \mathrm{LiClO}_{4}(25) /$ phenolic blends as a function of phenolic concentration (phr). A considerable increase in the conductivity is observed by adding a small quantity of the phenolic and the maximum ionic conductivity is achieved at the phenolic concentration of $15 \mathrm{phr}$. However, the conductivity drastically decreases to even lower than the original value at $20 \mathrm{phr}$ phenolic concentration. At $40^{\circ} \mathrm{C}$, the conductivity of $\mathrm{PEO}(100) / \mathrm{LiClO}_{4}(25) /$ phenolic(15) is about three times higher than that of the plain $\mathrm{PEO}(100) / \mathrm{Li}-$ $\mathrm{ClO}_{4}(25)$ system. However, the trend of the ionic conductivity is not consistent with the $T_{g}$ observed in Figure 2. It is interesting to note that specific interactions exist among $\mathrm{PEO}, \mathrm{LiClO}_{4}$, and the phenolic.

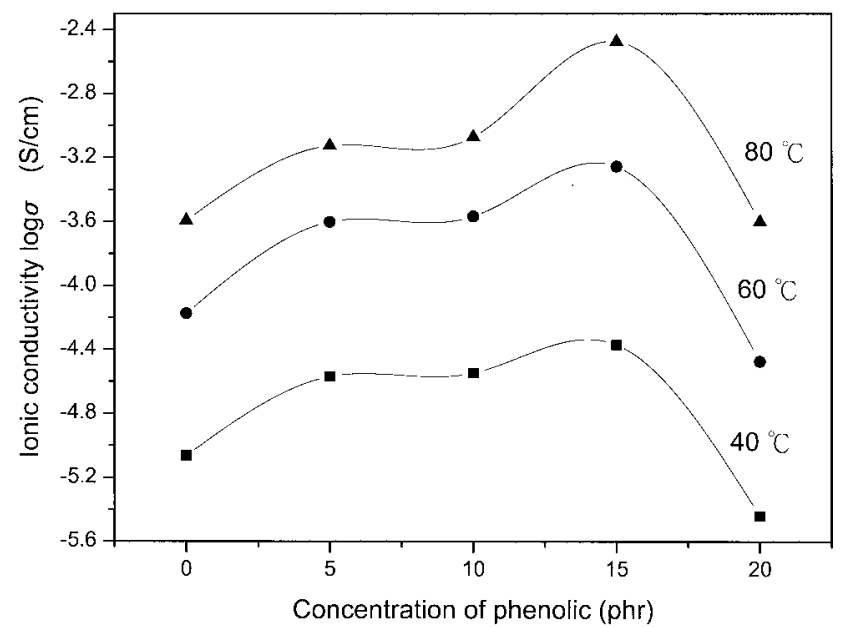

Figure 4 Dependency of ionic conductivity of PEO(100)/ $\mathrm{LiClO}_{4}(25) /$ phenolic with various phenolic concentrations at the same temperature: $(\square) 40^{\circ} \mathrm{C} ;(\mathbf{O}) 60^{\circ} \mathrm{C} ;(\boldsymbol{\Delta}) 80^{\circ} \mathrm{C}$.

\section{Infrared spectra}

FTIR spectroscopy is a powerful tool for analyzing changes in electrolytic systems, in particular, important information about intermolecular interaction in the $\mathrm{PEO} /$ phenolic $/ \mathrm{LiClO}_{4}$ electrolyte system. In the PEO-based polymer electrolyte, the $\mathrm{Li}^{+}$ion tends to associate with the oxygen atom of the PEO, forming a complex, given that the oxygen atom of PEO is a strong electron donor. ${ }^{24,25}$ Figure 5 presents the FTIR spectra for the $\mathrm{PEO}(100) / \mathrm{LiClO}_{4}(25) /$ phenolic with various phenolic concentrations ranging from 4000 to $400 \mathrm{~cm}^{-1}$. The assignments for major bands are listed in Table II..$^{24-27}$ As may be observed in Figure 5, the pure PEO has a major peak at $1114 \mathrm{~cm}^{-1}$ and two

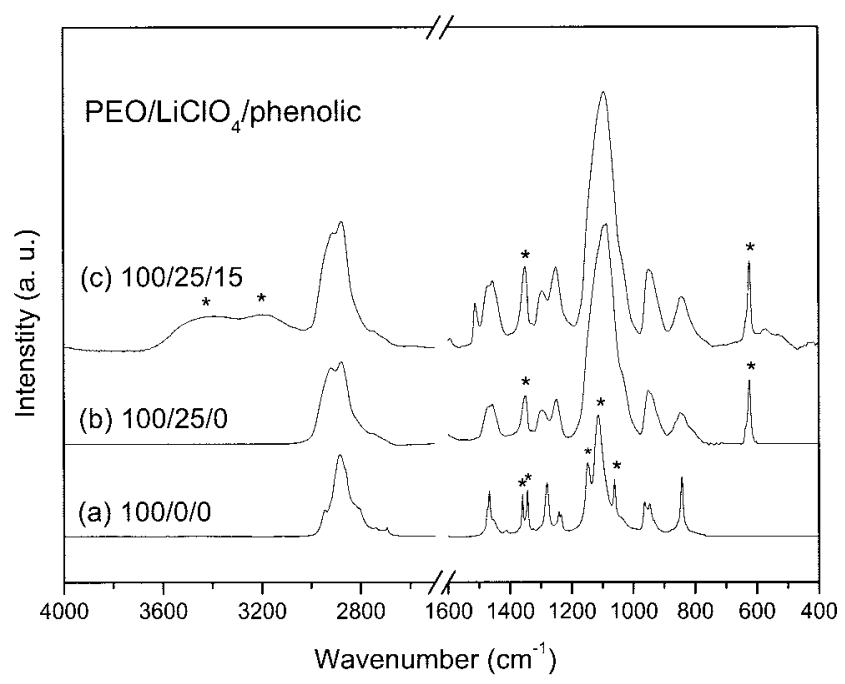

Figure 5 Infrared spectra in the $4000-400 \mathrm{~cm}^{-1}$ region of $\mathrm{PEO} / \mathrm{LiClO}_{4}$ /phenolic blends: (a) 100/0/0; (b) 100/25/0; (c) $100 / 25 / 15$. 
TABLE II

Observed Frequencies and Assignments of Infrared Bands of PEO(100)/ $\mathrm{LiClO}_{4}(25) /$ Phenolic(15) Blends, in a Cast Film at $27^{\circ} \mathrm{C}$, at $1 \mathrm{~cm}^{-1}$ Resolution of Experimental Spectra

$\mathrm{PEO} / \mathrm{LiClO}_{4} /$ phenolic complexes $\left(\mathrm{cm}^{-1}\right)$

Assignment

\begin{tabular}{ll}
$3500-3550^{\mathrm{a}}$ & Free $\mathrm{OH}$ \\
$3200-3600^{\mathrm{a}}$ & Hydrogen bonding \\
$2944,2883,2805^{\mathrm{b}}$ & $\mathrm{CH}_{2}$ or $\mathrm{CH}$ stretching \\
$1500,1600^{\mathrm{c}}$ & Phenyl \\
$1460^{\mathrm{b}}$ & $\mathrm{CH}_{2}$ bending \\
$1358,1342^{\mathrm{b}}$ & $\mathrm{CH}_{2}$ wagging \\
$1350^{\mathrm{b}}$ & Amorphous deformation \\
$1360,1343^{\mathrm{b}}$ & $\mathrm{Crystalline} \mathrm{deformation}$ \\
$1278,1241,1236,946,962^{\mathrm{b}}$ & $\mathrm{CH}_{2}$ deformation \\
$1060-1150^{\mathrm{b}}$ & $\mathrm{C}-\mathrm{O}-\mathrm{C}$ stretching \\
$844^{\mathrm{b}}$ & $\mathrm{CH}_{2}$ rocking \\
$600-650,933,1025-1100^{\mathrm{a}}$ & $\mathrm{ClO}_{4}^{-}$anion \\
\hline
\end{tabular}

${ }^{\text {a }}$ Values are for electrolytes.

b Values are for PEO.

${ }^{\mathrm{c}}$ Values are for phenolic.

minor peaks at 1060 and $1150 \mathrm{~cm}^{-1}$, all of which correspond to the $\mathrm{C}-\mathrm{O}-\mathrm{C}$ stretching motion. The adsorption of the $\mathrm{C}-\mathrm{O}-\mathrm{C}$ region becomes a broad peak with incorporation of $25 \mathrm{phr} \mathrm{LiClO}_{4}$ and the changes of the adsorption could be attributed to the electron surroundings of $\mathrm{C}-\mathrm{O}-\mathrm{C}$ being disturbed by the strong interaction of oxygen atom and lithium cation. In Figure 5(a), one may observe the bands at 1360 and $1343 \mathrm{~cm}^{-1}$, both of which correspond to the crystalline PEO phase. Furthermore, with the blends of $\mathrm{PEO}(100) / \mathrm{LiClO}_{4}(25)$ and $\mathrm{PEO}(100) / \mathrm{LiClO}_{4}(25) /$ phenolic(15), the two crystalline split peaks are replaced by a broad band roughly centered at 1350 $\mathrm{cm}^{-1}$, which corresponds to the amorphous regions in PEO. Therefore, blends of $\mathrm{PEO}(100) / \mathrm{LiClO}_{4}(25)$ and $\mathrm{PEO}(100) / \mathrm{LiClO}_{4}(25) /$ phenolic(15) are amorphous, which is also consistent with the previous thermograms in Figure 1.

The hydroxyl-stretching region of the $\mathrm{PEO} / \mathrm{phe}$ nolic blends was also examined. Figure 6 shows the infrared spectra in the 3700 to $2900 \mathrm{~cm}^{-1}$ region of the pure phenolic and $\mathrm{PEO}(100) / \mathrm{LiClO}_{4}(25) /$ phenolic blends containing various phenolic contents measured at $25^{\circ} \mathrm{C}$. From Figure 6 , the pure phenolic polymer is composed of two hydroxyl components: a very broad band, centered at $3340 \mathrm{~cm}^{-1}$, is attributed to the wide distribution of the hydrogen bonded hydroxyl group and a relatively narrow band at $3525 \mathrm{~cm}^{-1}$ is caused by the free hydroxyl group. For the blend of $\mathrm{PEO}(100) / \mathrm{LiClO}_{4}(25) /$ phenolic(5), a shoulder can be found at $3225 \mathrm{~cm}^{-1}$, which can be attributed to the intermolecular hydroxyl-ether bond. By increasing the phenolic content in the $\mathrm{PEO}(100) / \mathrm{LiClO}_{4}(25) /$ phenolic blend, the intensity of the free hydroxyl group $\left(3525 \mathrm{~cm}^{-1}\right)$ apparently decreases and even disap- pears. Meanwhile, the broad hydrogen bonded hydroxyl band of the phenolic shifts to a lower frequency and the intensity of the intermolecular hydroxyl-ether bond $\left(\sim 3225 \mathrm{~cm}^{-1}\right)$ increases with increasing phenolic content. The switch of the intramolecular hydroxyl-hydroxyl bond into the intermolecular hydroxyl-ether bond indicates that the hydrogen-bonding interaction between the PEO ether group and the hydroxyl group of phenolic is increased, causing this change. The average strength of the intermolecular interaction can be estimated by the extent of frequency difference $(\Delta \nu)$ between the hydrogen-bonded hydroxyl absorption and free hydroxyl absorption, which can be used as a measure of the average strength of the intermolecular interactions. ${ }^{21-23,28-31}$ The $\Delta \nu$ increases with increase of the phenolic content, which is higher than the self-associated hydroxyl of the phenolic $\left(\Delta \nu=185 \mathrm{~cm}^{-1}\right)$. Furthermore, the peak at about $3225 \mathrm{~cm}^{-1}$ shifts to a lower frequency because of the strong interaction of intermolecular hydrogen bonding, and the strongest interaction can be observed at 15 phr phenolic. However, the peak shifts back at 20 phr phenolic content and this phenomenon can be related to the stronger self-association of higher phenolic content at the expense of the intermolecular hydrogen bonding. ${ }^{35,36}$ The above results indicate that strong hydrogen bonding exists between $\mathrm{PEO}$ and

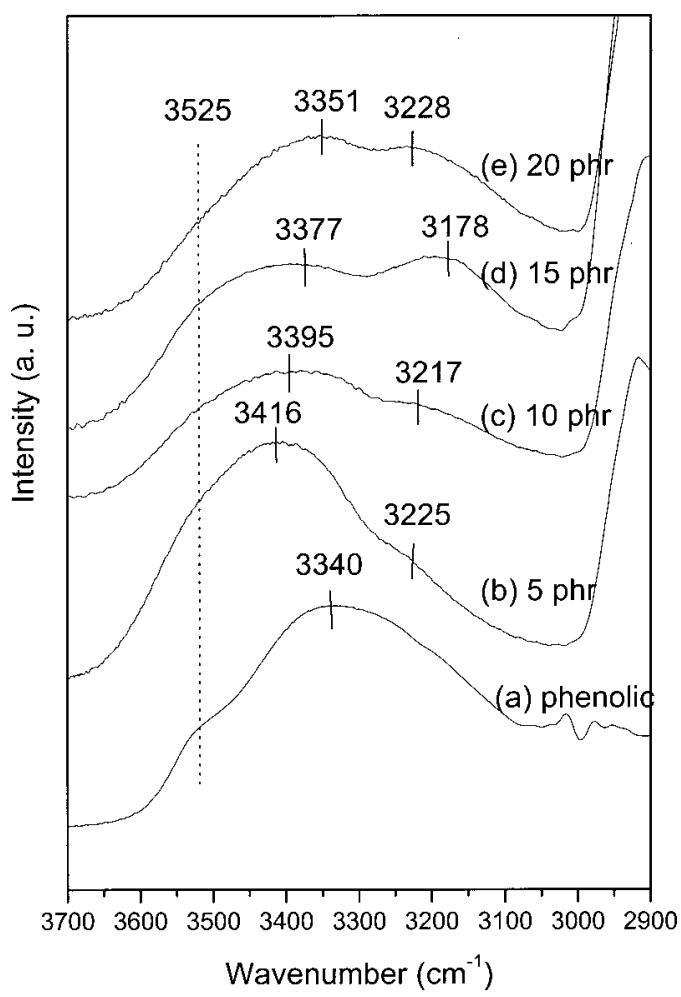

Figure 6 Infrared spectra in the $3700-2900 \mathrm{~cm}^{-1}$ region of $\mathrm{PEO} / \mathrm{LiClO}_{4} /$ phenolic with various phenolic concentrations: (a) pure phenolic; (b) $100 / 25 / 5$; (c) 100/25/10; (d) 100/25/15; (e) 100/25/20. 


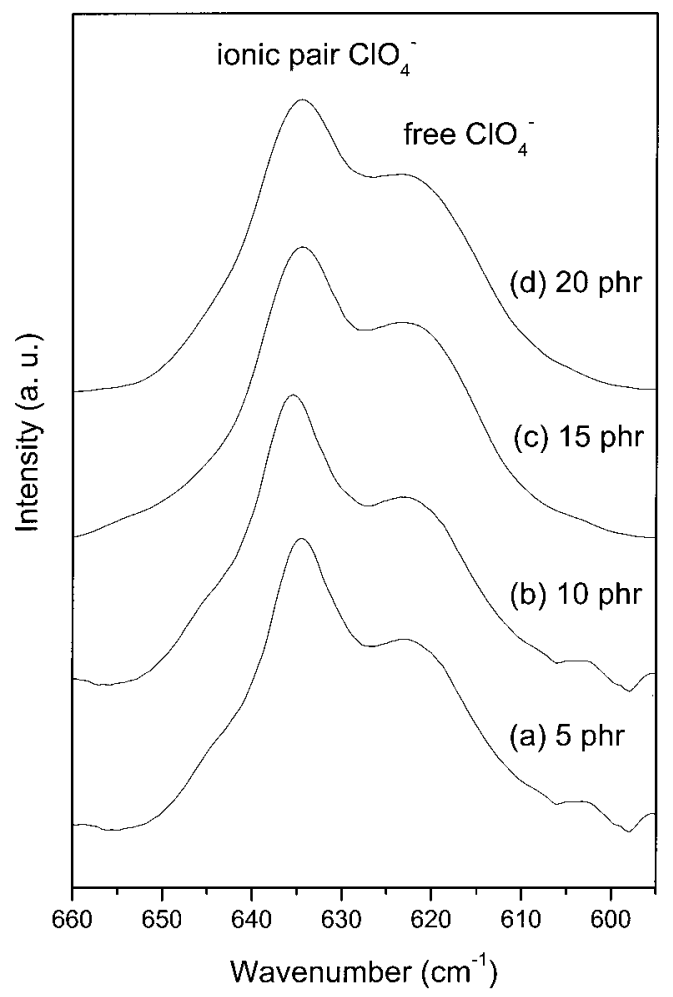

Figure 7 Infrared spectra in the $660-600 \mathrm{~cm}^{-1}$ region of $\mathrm{LiClO}_{4} /$ phenolic with various phenolic concentrations: (a) 25/5; (b) 25/10; (c) 25/15; (d) 25/20.

phenolic and the strongest intermolecular hydrogen bonding is for the $\mathrm{PEO}(100) / \mathrm{LiClO}_{4}(25) /$ phenolic(15) blend.

A similar trend is also observed from the $\nu\left(\mathrm{ClO}_{4}^{-}\right)$ internal mode of the $\mathrm{ClO}_{4}^{-}$anion. The characteristic $\nu\left(\mathrm{ClO}_{4}^{-}\right)$mode of the lithium perchlorate $\left(\mathrm{LiClO}_{4}\right)$ is sensitive to the change of the local anionic environment. ${ }^{14,25-27}$ According to previously reported studies, $^{32-34}$ the component observed at about $624 \mathrm{~cm}^{-1}$ was assigned to the "free" anion, which does not interact directly with the lithium cation. Components at about $635 \mathrm{~cm}^{-1}$ have been attributed to contact ion pairs. To clarify the interaction between the phenolic and lithium salts, typical infrared spectra in the $\nu\left(\mathrm{ClO}_{4}^{-}\right)$, ranging from 660 to $595 \mathrm{~cm}^{-1}$ at various phenolic concentrations of the $\mathrm{LiClO}_{4}(25) /$ phenolic electrolyte system at room temperature, are presented in Figure 7. A strong adsorption band at about 635 $\mathrm{cm}^{-1}$ and a relatively weaker peak at about $624 \mathrm{~cm}^{-1}$ can be observed. However, no chemical shift or intensity changes were observed for both adsorptions $\left(\sim 635\right.$ and $\left.\sim 624 \mathrm{~cm}^{-1}\right)$ when varying the phenolic contents. This observation can be interpreted as that the interaction between phenolic and lithium salt is insignificant. In other words, the lithium salt cannot be completely dissolved in the phenolic.

Figure 8 presents the same range of typical infrared spectra in the $\nu\left(\mathrm{ClO}_{4}^{-}\right)$spectra at various phenolic concentrations for $\mathrm{PEO}(100) / \mathrm{LiClO}_{4}(25) /$ phenolic blends at room temperature. In the absence of the phenolic, a large adsorption band at about $624 \mathrm{~cm}^{-1}$ and a shoulder at about $635 \mathrm{~cm}^{-1}$ are evident, corresponding to the "free" and ion pair, respectively. ${ }^{14,27}$ The peak at about $635 \mathrm{~cm}^{-1}$ decreases in intensity with the increase of the phenolic concentration and nearly disappears when the phenolic concentration is at $15 \mathrm{phr}$. In the blend of $\mathrm{PEO}(100) / \mathrm{LiClO}_{4}(25) /$ phenolic(15), the "free" fraction of $\nu\left(\mathrm{ClO}_{4}^{-}\right)$dominates over the fraction of ion pair, indicating that the lithium salt is nearly dissolved in the $\mathrm{PEO}(100) / \mathrm{LiClO}_{4}(25) /$ phenolic(15) blend. However, the intensity of the ion pair peak increases drastically with a further increase of the phenolic concentration at $20 \mathrm{phr}$. The IR data on the $\nu\left(\mathrm{ClO}_{4}^{-}\right)$mode confirm that the addition of phenolic facilitates the ether group interacting with lithium ion, thus causing a reduction of the attractive force between cationic and anionic ions of the $\mathrm{LiClO}_{4}$. However, the quantity of the ion pair increases when the addition of the phenolic is greater than $15 \mathrm{phr}$ and this trend can be related to the strong interaction of hydrogen bonding as evidenced in the previous results (Fig. 6). The higher interaction of hydrogen bonding results in higher compaction between phenolic and PEO; thus the lithium salt is crowded out of this fully compatible system. From the IR results it can

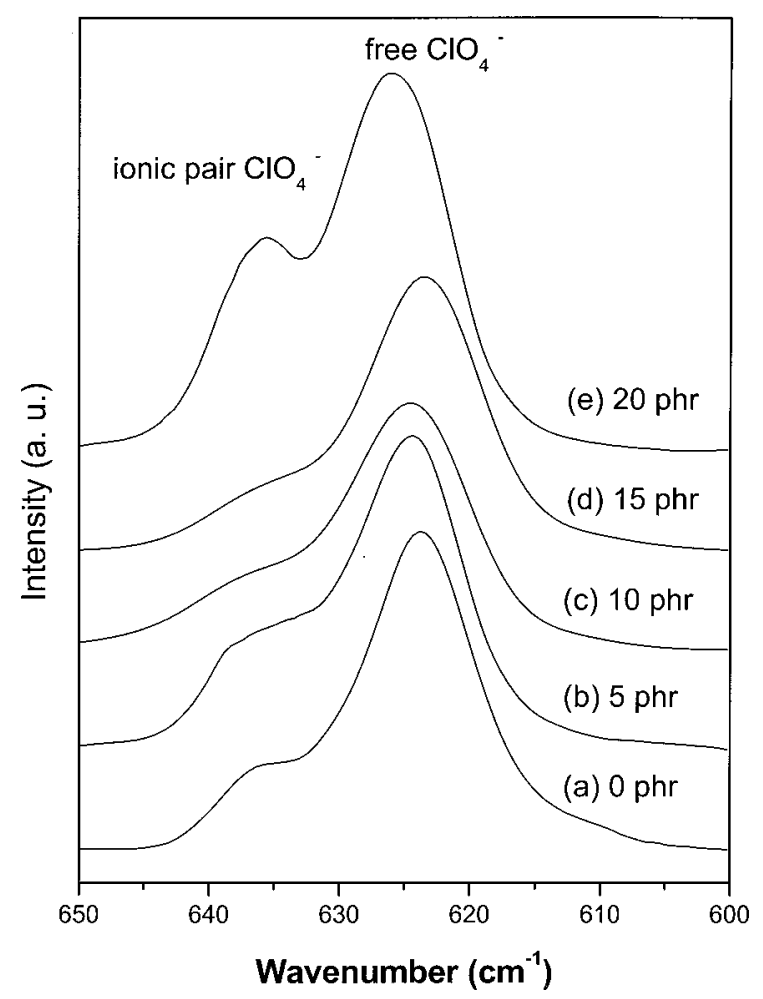

Figure 8 Infrared spectra in the $660-600 \mathrm{~cm}^{-1}$ region of $\mathrm{PEO} / \mathrm{LiClO}_{4} /$ phenolic with various phenolic concentrations: (a) $100 / 25 / 0$; (b) $100 / 25 / 5$; (c) 100/25/10; (d) 100/25/ 15 ; (e) $100 / 25 / 20$. 
Type I :

PEO interaction $\mathrm{LiClO}_{4}$

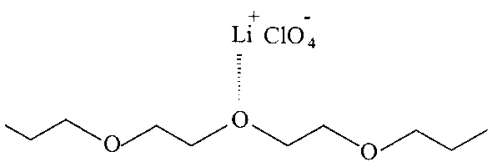

Type II :

PEO interaction phenolic
Type III:

\section{$\mathrm{PEO} / \mathrm{LiClO}_{4} /$ phenolic complexes}

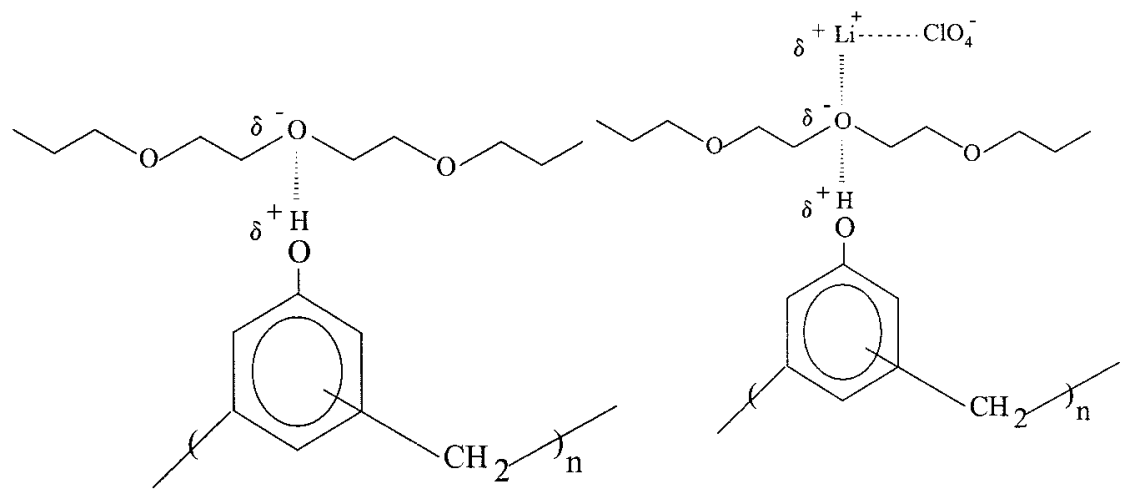

Scheme 1 Three proposed types of ionic association of the $\mathrm{PEO} / \mathrm{LiClO}_{4} /$ phenolic polymer electrolytes.

be concluded that the phenolic does not interact directly with the lithium salt, but the whole cationic charge environment is strongly influenced by the addition of phenolic resin in the $\mathrm{PEO} / \mathrm{LiClO}_{4} /$ phenolic blend.

Based on the above findings on the microstructure of $\mathrm{PEO} / \mathrm{LiClO}_{4} /$ phenolic polymer electrolytes, the total structural geometry is depicted in Scheme 1. The type I complex describes the solvated $\mathrm{Li}^{+} \ldots \mathrm{ClO}_{4}^{-}$ ionic pair complexing with oxygen atom of PEO. The type II complex describes the hydrogen bonding between PEO and phenolic. The type III complex describes the intermolecular interaction of the PEO/Li$\mathrm{ClO}_{4} /$ phenolic polymer electrolyte. This illustrates that the hydrogen bonding induced not only a positive charge on hydroxyl groups but also a negative charge on oxygen atoms of PEO. The electrons surrounding the ether oxygen were attracted by the higher electronegativity of the hydroxy group. The hydroxyl group of the phenolic plays the role of donating electrons in the hydrogen bonding system and induces the oxygen atom on PEO to become partially negative (type II complex). This induced, partially negative charge, on the oxygen atom will result in a stronger Lewis base. Furthermore, the lithium cation can be dissolved in the PEO/phenolic composite system, attributed to the strong Lewis base-acid interaction (type III complex). This induced, partially negative charge on the oxygen atom is also confirmed by the previous IR results (Fig. 6). Figure 6 indicates that the blend with 15 phr phenolic possesses the strongest ability to dissolve the $\mathrm{LiClO}_{4}$, corresponding to the highest intensity of the "free" ion of $\nu\left(\mathrm{ClO}_{4}^{-}\right)$. The optimum quantity of phenolic (15 phr) can also be related to the conductivity results shown in Figure 4 . Therefore, it can be concluded that the addition of phenolic causes a change in the charge environment of the oxygen atom of the $\mathrm{PEO}$, which in turn induces a negative charge on the ether group and increases the quantity of "free" anions.

\section{Dielectric property}

It is well known that the addition of a plasticizer into a polymer matrix is able to increase its dielectric constant over that of the polymer host because the plasticizer facilitates the dissociation of ions and increases the number of effective charge carriers. The dielectric constant is of particular significance for ionic conducting polymers. Figure 9 presents the effect of phenolic concentration on the PEO dielectric constant at 27 and $40^{\circ} \mathrm{C}$ and constant frequency of $100 \mathrm{~Hz}$. The curves in Figure 9 indicate that the dielectric constant increases with increasing phenolic concentration. The change in dielectric constant can be attributed to the partially negative charges induced by the hydrogen-bonding interaction. The blend containing a lower phenolic content induces fewer negative charges to orient in the direction of the applied field. Alternatively, for the blend with high phenolic content, a greater fraction of hydrogen bonding is able to induce more negative charges and results in a higher dielectric constant. Because of the higher mobility of the polymer matrix, a higher temperature also results in a higher dielectric constant of the composite, as would be expected.

\section{${ }^{7}$ Li chemical shift of NMR spectra}

For qualitative analysis of the lithium cation dynamics in the $\mathrm{PEO} / \mathrm{LiClO}_{4} /$ phenolic composite electrolyte, measurements of the spin-lattice relaxation time $T_{1}$ of ${ }^{7} \mathrm{Li}$ were carried out. The plot of the $T_{1}$ decay for the 


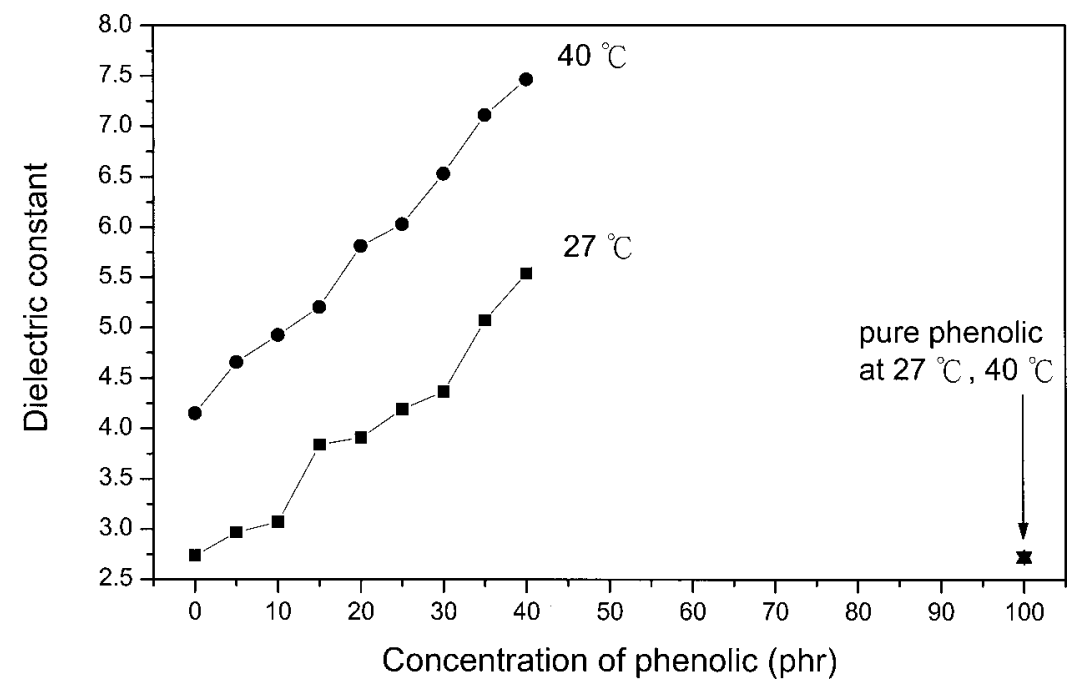

Figure 9 Dependency of dielectric constant of $\mathrm{PEO}(100) /$ phenolic with various concentrations of phenolic at the same temperature: $(\mathbf{\square}) 27^{\circ} \mathrm{C} ;(\mathbf{O}) 40^{\circ} \mathrm{C} ;(\mathbf{\Delta})$ pure phenolic at $27^{\circ} \mathrm{C} ;(\boldsymbol{\nabla})$ pure phenolic at $40^{\circ} \mathrm{C}$.

${ }^{7} \mathrm{Li}$ magnetization in the $\mathrm{PEO} / \mathrm{LiClO}_{4} /$ phenolic as a function of phenolic content is shown in Figure 10. The addition of phenolic clearly gives higher mobility of the lithium cation, as shown by the gradually decreasing relaxation time values $\left(T_{1}\right)$ for increasing phenolic concentration and the highest mobility is found at $15 \mathrm{phr}$ phenolic. However, the $T_{1}$ increases with further increase of the phenolic content (20 phr). The increase of $T_{1}$ corresponds to the lower mobility of the lithium cation. This observed trend can be related to the formation of hydrogen bonding between phenolic and PEO. Earlier results indicated that the addition of phenolic is able to induce a negative charge on the ether group of PEO and causes stronger interaction between the ether group and lithium cation. This induced negative charge on the ether group results in a strong Lewis base to dissolve the lithium salt more easily, and further disturbs the attractive force of the lithium salt, resulting in the higher mobility of lithium cation (lower $T_{1}$ ). From earlier results, in Figure 6, the increase in $T_{1}$ of lithium cation at $\mathrm{PEO}(100) / \mathrm{Li}-$ $\mathrm{ClO}_{4}(25) /$ phenolic(20) can be attributed to the lithium salts being crowded out in this more compact system.

\section{Thermal degradation analysis}

A thermal gravimetric analyzer was used to carry out experiments on the weight loss and thermal decom-

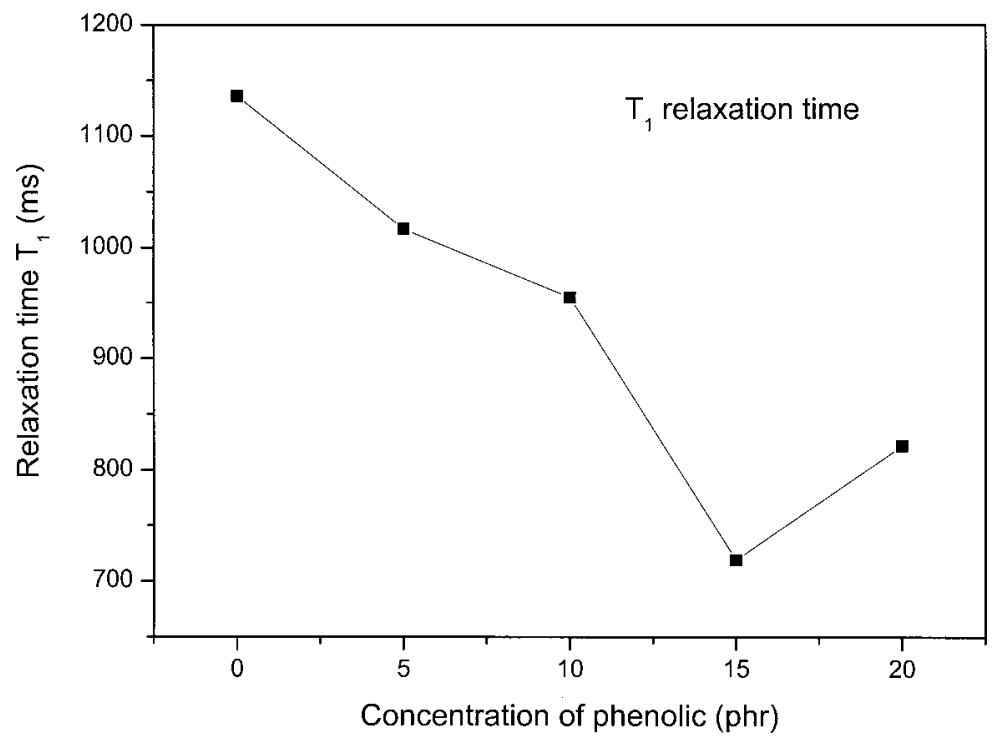

Figure 10 Relaxation time $\left(T_{1}\right)$ scaled ${ }^{7} \mathrm{Li} \mathrm{CP} / \mathrm{MAS}$ NMR spectra of $\mathrm{PEO}(100) / \mathrm{LiClO}_{4}(25) /$ phenolic with various phenolic contents. 


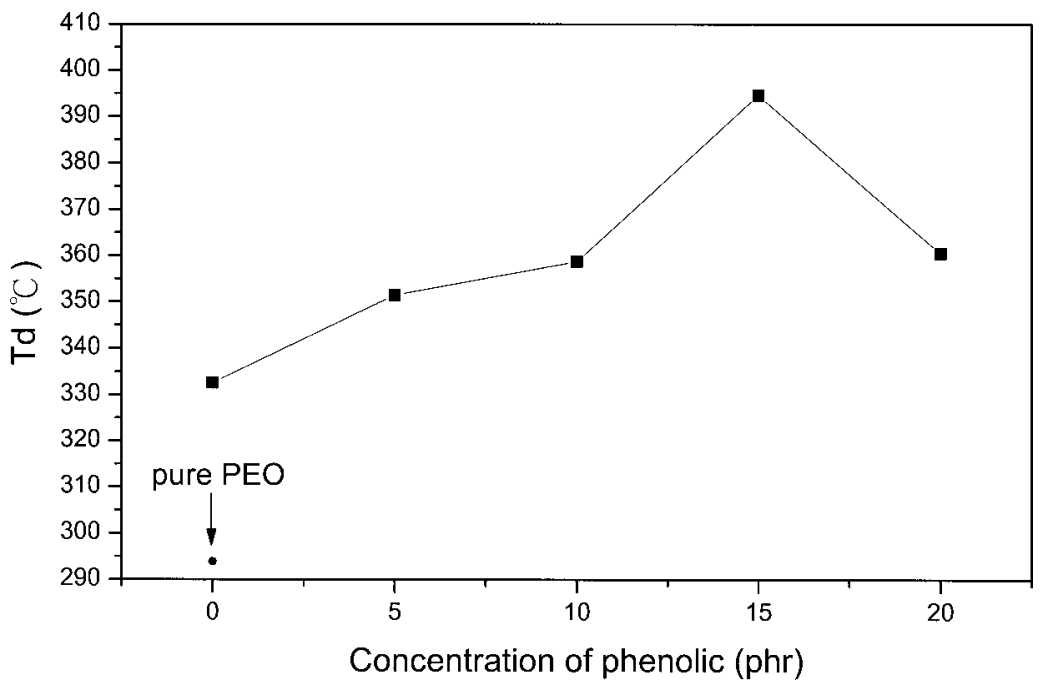

Figure 11 Thermal degradation temperature of $\mathrm{PEO}(100) / \mathrm{LiClO}_{4}(25) /$ phenolic blends with various phenolic concentrations.

position behavior for $\mathrm{PEO} / \mathrm{LiClO}_{4}$ /phenolic electrolytes. Figure 11 presents the thermal degradation temperature $\left(T_{d}\right)$ of $\mathrm{PEO}(100) / \mathrm{LiClO}_{4}(25) /$ phenolic blends as a function of phenolic concentrations. A similar trend was obtained: the $T_{d}$ value increases with the increase in phenolic content and attains a maximum value when the phenolic concentration is at 15 phr. Subsequently, the $T_{d}$ decreases with further increase in phenolic content. The $T_{d}$ of the plain PEO is $294^{\circ} \mathrm{C}$ and that of pure phenolic is $591^{\circ} \mathrm{C}$. With the incorporation of $25 \mathrm{phr} \mathrm{LiClO}_{4}$ into PEO [PEO(100)/ $\left.\mathrm{LiClO}_{4}(25)\right]$, the $T_{d}$ increases distinctly from 294 to $333^{\circ} \mathrm{C}$. Such a change in thermal stability behavior can be attributed to the formation of a pseudo-crosslinked system by the interaction of PEO and lithium cation. With the addition of the phenolic concentration in the $\mathrm{PEO}(100) / \mathrm{LiClO}_{4}(25) /$ phenolic blend, the $T_{d}$ increases and reaches the maximum value $\left(369^{\circ} \mathrm{C}\right)$ at $15 \mathrm{phr}$ phenolic. However, with a further increase of the phenolic concentration $(20 \mathrm{phr})$, a decrease in $T_{d}\left(361^{\circ} \mathrm{C}\right)$ can be observed. The changes of $T_{d}$ are strongly related to the interaction of hydrogen bonding attributed to the formation of pseudo-crosslinks between hydroxyl groups and ether groups. This trend of $T_{d}$ is also consistent with conductivity, IR, and $T_{1}$ results.

\section{CONCLUSIONS}

This study demonstrated that the addition of an optimum content of phenolic is able to increase the ionic conductivity of the poly(ethylene oxide)-based electrolyte by about 2 orders of magnitude relative to the plain system. DSC, FTIR, DEA, and solid-state NMR studies indicate that hydrogen bonding is present between $\mathrm{PEO}$ and phenolic in the $\mathrm{PEO} / \mathrm{LiClO}_{4} /$ phenolic composite electrolyte system. The phenolic does not directly interact with the lithium cation; on the contrary, the incorporation of the phenolic is able to induce a partial negative charge on the ether group of PEO by the strong hydrogen-bonding interaction between the hydroxyl group and the ether group. Furthermore, the ether group on $\mathrm{PEO}$, possessing a stronger negative charge, is more effective in disturbing the attractive force between the lithium anion and cation and leads to the formation of a higher concentration of "free" anion and thus higher conductivity. This investigation demonstrated that the blend of $\mathrm{PEO}(100) /$ $\mathrm{LiClO}_{4}(25) /$ phenolic(15) possesses the highest ionic conductivity, attributed to the strongest hydrogen bonding interaction between PEO and phenolic. The optimum ionic conductivity was obtained from the balanced attractive forces among the oxygen atom of PEO, hydroxyl groups, and the lithium cation and anion.

\section{References}

1. Fenton, D. E.; Parker, J. M.; Wright, P. V. Polymer 1973, 3, 589.

2. Wright, P. V. Br Polym J 1975, 7, 319.

3. Armand, M. B. Solid State Ionics 1983, 9/10, 745.

4. Armand, M. B. Annu Rev Mater Sci 1986, 16, 245.

5. Scrosati, B. In: Polymer Electrolyte Reviews; MacCallum, J. R.; Vincent, C. A., Eds.; Elsevier Applied Science: New York, 1989; p. 315.

6. Scrosati, B. In: Applications of Electroactive Polymers; Scrosati, B., Ed.; Chapman \& Hall: New York, 1993; p. 251.

7. Chao, S.; Wrighton, M. S. J Am Chem Soc 1987, 109, 2197.

8. Ratner, M. A.; Shriver, D. F. Chem Rev 1988, 88, 109.

9. Wang, L.; Yang, B.; Wang, X. L.; Tang, X. Z. J Appl Polym Sci 1999, 71, 1711.

10. Wang, X. L.; Li, H.; Tang, X. Z.; Chang, F. C. J Appl Polym Sci Polym Phys Ed 1999, 37, 837.

11. Skaarup, S.; West, K.; Zachan-Christiansen, B. Solid State Ionics 1988, 28-30, 975. 
12. Plocharski, J.; Wieczorek, W. Solid State Ionics 1998, 28-30, 979.

13. Liquan, C. In: Materials for Solid State Batteries; Chowdari, B. V.; Radhakrishna, S., Eds.; World Scientific: Singapore, 1988; p. 69.

14. Quartarone, E.; Mustarelli, P.; Magistris, A. Solid State Ionics 1998, 110, 1 .

15. Zhong, Z.; Guo, Q. Polymer 1998, 39, 517.

16. Penning, J. P., John, M. R. S. Macromolecules 1996, $29,77$.

17. Stotele, J. J.; Soldi, V.; Pires, A. T. N. Polymer 1997, 38, 1179.

18. Chu, P. P.; Wu, H.-D. Polymer 2000, 41, 101.

19. Wu, H. D.; Ma, C. C. M.; Li, M. S.; Su, Y. F.; Wu, Y. D. J Compos Part A: Appl Sci Manuf 1997, 28A, 895.

20. Wu, H. D.; Lee, C. T.; Ma, C. C. In: Proceedings of SAMPE Technical Conference, October 28, 1997, Orlando, FL; No. 29, 653.

21. Wu, H. D.; Chu, P. P.; Ma, C. C. M. Polymer 1997, 38, 5419.

22. Coleman, M. M.; Serman, C. J.; Painter, P. C. Macromolecules 1987, 20, 226

23. Kim, H. I.; Pearce, E. M.; Kwei, T. K. Macromolecules 1989, 22, 3374.

24. Ennari, J.; Neelov, I.; Sundholm, F. Comput Theor Polym Sci 2000, 10, 403
25. Lin-Vien, D.; Colthup, N. B.; Fately, W. G.; Grasselli, J. G. Infrared and Raman Characteristic Frequencies of Organic Molecules; Academic Press: San Diego, CA, 1991.

26. Pretsch; Clerc; Seibl; Simon. In: Table of Spectral Data for Structure Determination of Organic Compounds; Biemann, K., Ed.; Springer-Verlag: Berlin/Heidelberg/New York, 1983.

27. Nakanishi, K.; Solomon, P. H. Infrared Absorption Spectroscopy; K. N.: New York, 1976.

28. Coleman, M. M.; Graf, J. F.; Painter, P. C. Specific Interaction and Miscibility of Polymer Blends; Technomic: Lancaster, PA, 1991.

29. Purcell, K. F.; Drago, R. S. J Am Chem Soc 1968, 89, 2874.

30. Moskala, E. J.; Coleman, M. M. Polym Commun 1983, $24,207$.

31. Moskala, E. J.; Varnell, D. F.; Coleman, M. M. Polymer 1985, 26, 228.

32. Schantz, S. J Appl Phys 1988, 64, 2039.

33. Miller, A. G. J Phys Chem 1985, 89, 1193.

34. Frech, R. Electrochim Acta 1992, 37, 1499.

35. Dai, Y.; Greenbaum, S.; Golodnitsky, D.; Strauss, E.; Peled, E.; Rosenberg, Yu. Solid State Ionics 1998, 106, 25.

36. Chu, P. P.; Howard, J. J. Macromol Symp 1994, 86, 229. 